\title{
Analisis Usahatani Dan Keunggulan VUB Inpara 3
}

\author{
Firdaus, Adri \\ Balai Pengkajian Teknologi Pertanian (BPTP) Jambi, Indonesia \\ Email : fird6101osa@gmail.com
}

\begin{abstract}
ABSTRAK
Analisis Usahatani dan Keunggulan VUB Inpara 3. Penelitian dilaksanakan di Desa Rawa Medang, Kecamatan Batang Asam, Kabupaten Tanjung Jabung Barat, Provinsi Jambi. Penelitian dilaksanakan pada bulan Agustus - September 2020, dengan tujuan mengetahui kelayakan usahatani dan keunggulan Inpara 3. Metode penelitian survey terhadap 10 orang petani yang tergabung dalam kelompok tani Karya Mukti. Hasil penelitian menunjukkan bahwa petani responden berada pada usia produktif yaitu 3553 tahun. Tingkat pendidikan Sekolah Dasar (SD) $40 \%$ dan SLTP $60 \%$. Rata-rata kepemilikan lahan seluas 1,2 ha. Jumlah tanggungan anggota keluarga 3-5 orang. Ratarata hasil yang diperoleh $5.750 \mathrm{~kg} / \mathrm{ha}$ GKP dengan harga jual Rp 4.300/kg. Alokasi input produksi untuk pembayaran gaji upah $(71,64 \%)$, jauh lebih tinggi dibandingkan untuk pembelian bahan (28,36\%). Total penerimaan dari usahatani padi Rp. 24.725.000,-/ha/musim tanam (MT) dengan pendapatan Rp.16.347.000,-/ha/MT. Nisbah penerimaan dengan biaya (R/C) 2,95 Titik Impas Produksi (TIP) 1948,4 kg/ha dan Ttitik Impas Harga (TIH) Rp.1457,0 /kg.
\end{abstract}

Kata Kunci: Analisis, Usahatani, VUB, keunggulan, Inpara 3

\section{PENDAHULUAN}

Provinsi Jambi dengan luas wilayah 5,1 juta hektar terdiri dari lahan kering seluas 2,65 juta ha dan lahan pertanian tanaman pangan seluas 352.410 ha. Berdasarkan identifikasi dan karakterisasi Agro-ekosistem Zone / AEZ terdapat kurang lebih 1.380.700 ha lahan kering untuk lahan pertanian yang sesuai untuk pengembangan tanaman padi gogo, jagung dan palawija, sedangkan lahan yang sesuai untuk tanaman padi sawah 246.482 ha. Tanaman padi dan palawija merupakan komoditas penting di Provinsi Jambi sehingga menjadi prioritas dalam program pertanian (Busyra et al 2003).

Usahatani padi sawah di Provinsi Jambi dilakukan pada berbagai agroekosistem, seperti lahan sawah irigasi, tadah hujan, lahan pasang surut dan lahan lebak. Luas lahan sawah irigasi 40.703 ha, lahan tadah hujan 39.884 ha, pasang surut 31.385 ha, dan lebak 25.157 ha (BPS Provinsi Jambi, 2016). Hal ini menunjukan bahwa 
provinsi jambi merupakan wilayah potensial potensi tanaman pangan yang memiliki peluang untuk meningkatkan produktivitasnya. Rata-rata Produktivitas padi sawah di Provinsi Jambi masih rendah yaitu 43,79 ku/ha, dan padi ladang 29,71 ku/ha.

Peningkatan produktivitas dan produksi padi harus terus dilakukan untuk meningkatkan pendapatan dan kesejahteraan petani serta menjamin ketahanan pangan. Penggunaan varietas unggul padi yang berpotensi hasil tinggi dan semakin membaiknya mutu usahatani seperti pengolahan tanah, pemupukan dan cara tanam telah berhasil meningkatkan produktivitas padi (Zaini, et all, 2004).

Potensi sawah Kecamatan Batang Asam yang ditopang sistem irigasi teknis yang bagus disebut irigasi terbaik di Provinsi Jambi. Rata-rata petani padi Sri Agung dan Rawa Medang mempunyai produktivitas 5,5-6 ton/ha GKG. 2018). Pola tanam yang diterapkan pada wilayah yang memiliki system irigasi teknis yang bagus ini adalah padi-padi-palawija. Pada musim tanam (MT) I diusahakan tanaman padi, pada MT II masih tanaman padi dan pada MT III diusahakan palawija.

\section{METODOLOGI PENELITIAN}

\section{Metode Penelitian}

Penelitian dilaksankan di Desa Rawa Medang, Kecamatan Batang Asam, Kabupaten Tanjung Jabung Barat, Provinsi Jambi pada bulan Agustus - September 2020. Lokasi penelitian merupakan daerah sentra produksi padi sawah irigasi Kabupaten Tanjung Jabung Barat, maupun Provinsi Jambi. Metode penelitian survey yang merupakan study kasus pada petani yang tergabung dalam kelompok tani Karya Mukti. Data primer dikumpulkan menggunakan kuisioner. Data sekunder diperoleh dari study literature yang ada kaitannya dengan penelitian ini.

Data yang diambil berupa seluruh input dan output usahatani padi yang dilakukan petani tahun 2019/2020. Data Input usahatani mencakup semua biaya yang dikeluarkan dalam usahatani padi, baik biaya tetap maupun biaya variable. Sedangkan output dihitung dari semua hasil yang diperoleh. Penerimaan dihitung besarnya hasil yang diperoleh dikalikan dengan harga jual.

Biaya tetap adalah biaya yang tidak tergantung pada jumlah produksi dan sifatnya tidak habis dalam satu musim tanam, dihitung dalam satuan rupiah per hektar permusim. Biaya tetap dalam penelitian ini meliputi biaya yang dikeluarkan untuk membayar pajak bumi dan bangunan (PBB) dan membayar iyuran irigasi pada kelembagaan P3A, dan biaya yang dikeluarkan untuk penyusutan alat yang digunakan dalam usahatani. Rumus yang digunakan dalam menghitung penyusutan adalah : 
Penyusutan alat $=$ Nilai beli $t-$ Nilai sisa

$$
\text { Umur ekonomis }
$$

Biaya variable adalah biaya yang dikeluarkan dalam usahatani padi untuk pembelian semua sarana produksi dan pembayaran upah tenaga kerja, termasuk tenaga kerja dalam keluarga

\section{Analisis Data}

Data yang sudah terkumpul ditabulasi dan dianalisis secara deskriptif dengan menggunakan analisis usahatani yang meliputi :

\section{Analisis Biaya}

Untuk mengetahui jumlah biaya total (Total Cost) yang dikeluarkan petani dalam berusahatani padi dengan cara menjumlahkan biaya tetap total (Total Fixed Cost/FC) dengan biaya variable (Total Variable Cost) dengan rumus sebagai berikut (Suratiyah, 2006) :

$\mathrm{TC}=\mathrm{TFC}+\mathrm{TVC}$

Dimana ;

$\mathrm{TC}=$ Total biaya $($ Total Cost $)$

TFC $=$ Total biaya tetap $($ Total Fixed Cost $)$

$\mathrm{TVC}=$ Total biaya variable $($ Total Variable Cost $)$

2. Analisis Penerimaan Untuk mengetahui penerimaan total (Total Revenue/TR) TR adalah jumlah total produksi dikalikan dengan harga jual satuan produksi yang diperoleh petani dalam melaksanakan usahatani padi dengan menggunakan rumus sebagai berikut :

$$
\begin{aligned}
& \text { TR = Y.Hy } \\
& \text { Dimana } \\
& \text { TR = Penerimaan total } \\
& \text { Y = Jumlah produksi } \\
& \text { Hy = Harga produksi }
\end{aligned}
$$

\section{Analisis Pendapatan}

Pendapatan adalah penerimaan total ( Total Revenue / TR ) dikurangi dengan biaya total ( Total Cost / TC ) dengan menggunakan rumus sebagai berikut ;

$$
\begin{aligned}
& \pi=\mathrm{TR}-\mathrm{TC} \\
& \text { dimana } \\
& \pi \text { = Pendapatan }(\mathrm{Rp})
\end{aligned}
$$


$\mathrm{TR}=$ Penerimaan total

$\mathrm{TC}=$ Biaya total

4. Imbangan nisbah penerimaan dengan biaya ( R/C )

Nisbah penerimaaan dengan biaya (R/C) dihitung untuk melihat kelayakan usahatani. Apabila nilai $\mathrm{R} / \mathrm{C}<1$ maka usahatani dikatakan merugi atau tidak layak, jika $\mathrm{R} / \mathrm{C}=1$ maka usahatani dikatakan tidak beruntung dan juga tidak mengalami kerugian. Sedangkan bila $\mathrm{R} / \mathrm{C}>1$, maka usahatani dikatakan beruntung dan layak untuk diusahakan.

\section{Tititk Impas ( Break Event Point )}

Mempelajari hubungan antara biaya produksi, volume penjualan, maka dapat diketahui tingkat keuntungan serta kelayakan usahatani. Salah satu teknik dalam mempelajari hubungan antara biaya, penerimaan dan volume produksi adalah dengan menghitung titik impas produksi (Break Even Yield) dan titik impas harga (Break Even Price).

Analisis titik impas produksi dan titik impas harga sangat penting bagi usaha tani sehubungan dengan efisiensi produksi. Dengan alat analisis ini dapat diketahui pada tingkat produktivitas berapa usahatani padi memperoleh keuntungan, keuntungan normal ataupun mengalami kerugian. Analisis titik impas menghasilkan gambaran jumlah dan harga minimum yang akan diproduksi (Setiawan, 2008). TIP dan TIH dapat dirumusakan sebagai berikut:

TIP = Total Biaya $(\mathrm{TC}) /$ Harga Produksi

$\mathrm{TIH}=$ Total Biaya $(\mathrm{TC}) /$ Jumlah Produksi

6. Tingkat Pendidikan dan Usia serta Luas lahan garapan petani responeden Data tingkat pendidikan petani responden diambil yaitu tingkat pendidikan formal yang pernah diikuti dan menamatkannya. Sementara usia petani responden diambil untuk mengetahui tingkat usia produktif atau tidak produktif. Luas lahan garapan adalah luas lahan yang digarap untuk usahatani padi pada musim hujan (MH).

\section{HASIL DAN PEMBAHASAN}

\section{Penyebaran varietas padi di Provinsi Jambi.}

Penggunaan Varietas Unggul di Provinsi Jambi sudah bergeser dari varietas lama ke varietas unggul baru (VUB). Salah satu VUB yang sudah luas penanamannya hampir di seluruh kabupaten/kota di Provinsi Jambi yaitu Inpara 3. Inpara 3 menggeser pertanaman varietas lama seperti IR 42 dan Ciherang. (Tabel 1). 
Tabel 1. Distribusi perbanyakan benih sebar dari beberapa varietas (2013)

\begin{tabular}{|c|l|c|}
\hline No. & \multicolumn{1}{|c|}{ Varietas } & \% Penyebaran \\
\hline 1. & Inpara 3 & 43,2 \\
\hline 2. & Ciherang & 13,5 \\
\hline 3. & Inpari 13 & 12,6 \\
\hline 4. & Indragiri & 12,0 \\
\hline 5. & IR 42 & 5,7 \\
\hline 6. & Inpari 3 & 4,7 \\
\hline 7. & Cisokan & 4,5 \\
\hline 8. & Mekongga & 3,0 \\
\hline 9. & Lainnya & 0,8 \\
\hline & Jumlah & 100 \\
\hline
\end{tabular}

Sumber : UPTD Perbenihan Provinsi Jambi tahun 2013 (data diolah).

Empat varietas unggul yang mendominasi pertanaman padi di Provinsi Jambi pada tahun 2013 adalah Inpara 3 (43,2\%), Ciherang (13,5\%), Inpari 13 (12,6\%), dan Indragiri $(12,0 \%)$. Penyebaran keempat varietas ini didasarkan atas preferensi petani dan kesesuaian adaptasi varietas. Walaupun Inpara 3 dikhususkan untuk sawah rawa, namun cukup baik adaptasinya pada lahan irigasi dataran rendah (Adri dan Yardha, 2016., Badan Litbang Pertanian, 2009).

\section{Keunggulan VUB Inpara 3}

Pengakuan petani responden di Desa rawa Medang bahwa mereka sudah lama menanam VUB Inpara 3. Petani memilih VUB Inpara 3 untuk ditanam karena varietas ini memiliki beberpa keunggulan yang mereka rasakan. Beberapa manfaat yang mereka rasakan tersebut antara lain; warna gabah yang kuning mengkilat dan warna beras yang putih bersih menyebabkan petani tidak sulit untuk menjualnya dan bahkan mendapatkan harga jual lebih tinggi Rp 100,- per kg bila dibandingkan dengan gabah atau beras varietas lain. Keunggulan lain yang dirasakan petani ialah karena ketahanan varietas ini terhadap Hama : Agak tahan Wereng Batang Coklat Biotipe 3, penyakit blas, sesuai deskripsi varietasnya (Badan Litbang Pertanian, 2015). Namun ada hama sundep yang menyerang tanaman padi namun sangat sedikit, itupun tidak hanya Inpara 3 (Puslitbangtan, 2009). Disamping varietas Inpara 3 juga terdapat varietas lainnya yaitu Sijunjung, Melati namun jumlahnya tidak luas diusahakan petani.

\section{Karakterstik responden}

Karakteristik responden dilihat dari aspek umur, pendidikan, luas lahan garapan. Umur petani responden mulai dari 32-52 tahun. Dengan demikian semua responden termasuk kedalam usia produktif. Menurut Daniel (2005) dan Sukmaningrum dan Ali 
Imron (2017) penduduk usia produktif adalah yang berumur 15-64 tahun. Pada usia produktif ini kekuatan fisik masih mendukung dalam melakukan usahatani.

Tabel 2. Rata-rata Umur Petani Responden

\begin{tabular}{|c|c|c|}
\hline Umur (tahun) & $\begin{array}{c}\text { Jumlah } \\
\text { (orang) }\end{array}$ & $\begin{array}{c}\text { Perentase } \\
(\%)\end{array}$ \\
\hline $35-40$ & 4 & 40 \\
\hline $41-45$ & 3 & 30 \\
\hline $46-50$ & 2 & 20 \\
\hline $51-55$ & 1 & 10 \\
\hline Jumlah & 10 & 100 \\
\hline \multicolumn{2}{|c|}{ Sumber data Primer (2020) }
\end{tabular}

Tingkat pendidikan terbanyak dari petani responden adalah sekolah lanjutan Pertama (60\%). Sedangkan yang menamatkan pendidikan sampai tingkat sekolah dasar (40\%). Sehubungan dengan tingkat pendidikan petani. Lebih kanjut dikayakan oleh Sukmaningrum dan Ali Imron (2017) bahwa peningkatan SDM tidak hanya dibatasi peningkatan produktivitas petani. Namun, juga peningkatan kemampuan petani untuk lebih berperan dalam proses pembangunan.

Tabel 3. Rata-rata tingkat pendidikan

\begin{tabular}{|l|c|c|}
\hline Tingkat Pendidikan & $\begin{array}{c}\text { Jumlah } \\
\text { (orang) }\end{array}$ & $\begin{array}{c}\text { Perentase } \\
(\%)\end{array}$ \\
\hline Sekolah Dasar & 4 & 40 \\
\hline Lanjutan Pertama (SLTP) & 6 & 60 \\
\hline Jumlah & 10 & 100 \\
\hline
\end{tabular}

Sumber data Primer (2020)

Rata-rata kepemilikan lahan usaha petani seluas 1,2 ha atau dengan kisaran 0,5 -2,0 ha. Luas kepemilikan lahan yang terbanyak adalah lahan seluas 1 ha (40\%). Lahan usaha ini merupakan lahan milik sendiri atau petani penggarap pemilik. Lahan sawah di Desa Rawa Medang sangat produktif, dimana lahan dapat diusahakan tiga kali dalam setahun dengan pola pad-padi-palawija. 
Tabel 4. Rata-rata Luas Kepemilikan Lahan

\begin{tabular}{|c|c|c|}
\hline $\begin{array}{c}\text { Luas } \\
\text { Kepemilikan } \\
\text { Lahan }\end{array}$ & $\begin{array}{c}\text { Jumlah } \\
\text { (orang) }\end{array}$ & $\begin{array}{c}\text { Perentase } \\
(\%)\end{array}$ \\
\hline 0,5 & 2 & 20 \\
\hline 1,0 & 4 & 40 \\
\hline 1,5 & 2 & 20 \\
\hline 2,0 & 2 & 20 \\
\hline Jumlah & 10 & 100 \\
\hline
\end{tabular}

Sumber data Primer (2020)

\section{Produktivitas dan Analisis Usahatani.}

Rata-rata hasil yang diperoleh petani $5.750 \mathrm{~kg} / \mathrm{ha}$ GKP. Pada sawah irigasi teknis seperti di Desa Rawa Medang ini hasil masih bisa ditingkatkan sampai 7,52 ton GKP/ha (Badan Litbang Pertanian, 2014). Beberapa upaya yang dapat dilakukan untuk meningkatkan produktivitas padi lahan irigasi adalah dengan menerapkan konsep PTT (Pengelolaan tanaman Terpadu). sebagaimana yang disampaikan oleh BP2TP (2012) dan Zaini, dkk (2004).

Jumlah penerimaan usahatani padi sebesar Rp Rp 24.752.000,-/ha/MT dengan total pengeluaran sebesar Rp 8.378.00,-, sehingga pendapatan usahatani sebesar Rp 16.347.000,-/ha/MT. sementara penelitian yang dilakukan oleh Ariyanis ( 2009) didapatkan penerimaan usahatani padi lahan irigasi kecamatan Batang asam sebesar Rp 26.242.885,-/ha/MT dengan total biaya produksi sebesar Rp 7.371.915,- sehingga didapat rata-rata pendapatan petani sebesar Rp 18.870.970,-/ha/MT atau lebih tinggi Rp 2.523.970,- /ha/MT

Table 5. Rata-rata Biaya Tetap, Biaya Variabel dan Jumlah Biaya Usahatani

\begin{tabular}{|l|c|c|}
\hline \multicolumn{1}{|c|}{$\begin{array}{c}\text { Uraian } \\
\text { Biaya }\end{array}$} & Biaya (Rp ) & Persentase (\%) \\
\hline Biaya Tetap & $152.000,-$ & 1,8 \\
\hline $\begin{array}{l}\text { Biaya } \\
\text { Variabel }\end{array}$ & $8.226 .000,-$ & 98,2 \\
\hline $\begin{array}{l}\text { Jumlah } \\
\text { Biaya }\end{array}$ & $8.378 .000,-$ & 100 \\
\hline
\end{tabular}

Sumber data Primer (2020) 
Hasil perhitungan volume atau jumlah produksi minimum yang harus diperoleh untuk mencapai titik impas (break event point) dalam satu kali musim tanam digunakan rumus perhitungan TIP = Total Biaya (TC) / Harga Produksi, begitu juga dengan perhitungan titik impas harga dengan rumus $\mathrm{TIH}=$ Total Biaya (TC) / Jumlah Produksi.

Usahatani padi di lahan pasang surut pada musim hujan layak diusahakan karena perhitungan $\mathrm{R} / \mathrm{C}<1$ dan TIP dan TIH dibawah nilai produksi dan harga yang diperoleh lebih rendah dari produksi aktual dan harga jual produk yang diterima petani atau dengan kata lain produksi yang diperoleh diatas angka minimal produksi (TIP) dan harga jual diperoleh diatas harga minimal (TIH).

Table 6. Rata-rata Penerimaa, Pendapatan, R/C, TTIP dan TIH Usahatani

\begin{tabular}{|l|l|}
\hline \multicolumn{1}{|c|}{ Uraian } & Biaya (Rp)Padi \\
\hline Penerimaan ( Rp /ha ) & $24.725 .000,-$ \\
\hline Pendapatan ( Rp /ha ) & $16.347 .000,-$ \\
\hline R/C & 2,9 \\
\hline TIP (kg/ha) & 1948,4 \\
\hline TIH (Rp/kg) & 1457,0 \\
\hline
\end{tabular}

Sumber data Primer (2020)

\section{KESIMPULAN DAN SARAN}

\section{Kesimpulan :}

1. Produktivitas padi yang diperoleh petani sebanyak $5.750 \mathrm{~kg} \mathrm{GKP} / \mathrm{ha}$, dengan biaya usahatani variable sebesar $R p$ 8.226.000,- dan biaya tetap sebesar $R p$ 152.000,- per hektar per musim tanam

2. Dari hasil produksi tersebut petani mendapatkan Penerimaan usahatani sebesar Rp 24.752.000,- dan pendapatan sebesar Rp 16.347.000,-

3. Usahatani padi di Desa Rawa Medang sangat layak dan menguntungkan, hal ini dilihat dari indicator R/C sebesar 2,95. TIP sebesar 1.948, $4 \mathrm{~kg} /$ ha dan harga diatas 1.457,- $\mathrm{Rp} / \mathrm{kg}$ juga suatu indikator bahwa usahatani layak dan menguntungkan karena produksi yang diperoleh $5.750 \mathrm{~kg} / \mathrm{ha}$ dan harga jual $\mathrm{Rp}$ Rp 4.300 per $\mathrm{kg}$.

4. Irigasi yang lancar dan baik menjadikan lahan sawah di Desa Rawa Medang sangat produktif dan dapat diusahakan 3 kali setahun dengan pola (Padi-PadiPalawija). 


\section{Saran}

Berdasarkan kesimpulan di atas, makan disarankan agar :

1. Guna meningkatkan produktivitas hasil padi maka, disarankan kepada petani berusaha meningkatkan penerapakan konsep Pengelolaan Tanaman Terpadu (Padi) sawah irigasi.

2. Guna meningkatkan efisiensi usahatani, disarankan kepada petani untuk mengurangi input usahatani biaya variable dari upah kerja, baik tenaga kerja upahan maupun tenaga kerja dalam keluarga.

\section{UCAPAN TERIMA KASIH}

Ucapan terima kasih disampaikan kepada Ketua Kelompok Tani Karya Mukti berserta anggota dan Petugas Penyuluh Lapangan (PPL) Desa Rawa Medang.

\section{DAFTAR PUSTAKA}

Adri dan Yardha. 2016. Keragaan Usahatani Dengan Pendekatan PTT dan Prosspek Pengembangan Padi Di Kawasan Pengembangan Padi Nasional - Jambi. Bunga Rampai “ Menguak Potensi Teknologi Spesifik lokasi Guna mencapai Kesejahteraan Petani" Pendekatan Pengkajian dan Pendukung Teknologi Ketahanan Panagan. Penerbit Kristal Multi Media 2016. ISBN : 978-602-74371-11

Aryanis, Miltiya. Analisis Pendapatan Usahatani Padi di Kecamatan Batang Asam Kabupaten Tanjung Jabung Barat. Jurnal_DIB014045_Miltia Aryanis_Agribisnis.pdf

Badan Litbang Pertanian. 2015. Deskripsi Varietas Unggul Baru Padi. Inbrida Padi Sawah (Inpari), Inbrida Padi Gogo (Inpago), Inbrida Padi Rawa (Inpara),, Hibrida Padi (Hipa). Badan Penelitian dan Pengembangan Pertanian, Kementerian Pertanian. 2015

Badan Litbang Pertanian. 2009. www.litbang.go.id>varietas. Diunduh tanggal 7 Oktober 2020.

Badan Pusat Statistik Provinsi Jambi.2016. Provinsi Jambi Dalam Angkat Tahun 2016. Balai Besar Pengkajian dan Pengembangan Teknologi Pertanian, BP2TP. 2012. Sistem Tanam Legowo. Penyusun Sarlan Abdulrachman, Nurwulan Agustiani, Indra Gunawan, dan Made Jena Mejaya. ISBN 978-979-504-064-6

Busyra, BS, N. Hasan, A. Yusri, Adri, dan Hery Nugroho. 2003. Zona Agroekologi Provinsi Jambi. Balai Pengkajian Teknologi Pertanian Jambi. Badan Litbang Pertanian.

Daniel, M. 2005. Metode Penelitian Sosial Ekonomi. PT. Bumi Aksara Jakarta 
DetikNews. 2009. Sumberdaya Manusia pertanian. Sabtu 21 Maret 2009. Diambil /disetir Rabu19 Agustus 2020.

Puslitbangtan. 2009. Masalah lapang Hama Penyakit, Hara Pada padi. Kerjasama Pusat penelitian tanaman paangan dengan International Rice Research Institute.

Setiawan, D,H., dan Agus Andoko. 2008. Petunjuk Lengkap Budi Daya Karet. Kiat Mengatasi Permasalahan Praktis. Penerbit PT.Agro Media Pustaka

Sukmaningrum dan Ali Imron. 2017. Sumber Daya Manusia Pertanian. Detik News Sabtu 21 Maret 2009. Diupload 19 AGustus 2020.

Suratiyah. 2006. Ilmu Usahatani. Penerbit Penebar Swadaya. Jakarta

Zaini, Z., Diah WS., dan Mahyudin Syam. 2004. Petujuk Lapang Pengelolaan Tanaman Terpadu (PTT) Padi Sawah. Meningkatkan Hasil dan Pendapatan Menjaga Kelestarian Lingkungan. Balai Pengkajian dan Pengembangan Teknologi Pertanian. Balai Pengkajian Teknologi Pertanian Sumatera Utara. Balai Pengkajian Teknologi Pertanian Nusa Tenggara barat. Balai Penelitian Tanaman Padi. International Rice Research Ins 